\title{
INVESTIGATION OF THE FORMATION PROCESS OF HAZARDOUS AND HARMFUL PRODUCTION FACTORS WHEN CUTTING A STONE FOR CONSTRUCTION WORKS
}

\author{
Alla Bezpalova \\ Department of Building Management and Labor Protection \\ Odessa State Academy of Civil Engineering and Architecture \\ 4 Didrichson str., Odessa, Ukraine, 65044 \\ bespalova-a-v@mail.ru \\ Vladimir Lebedev \\ Department of Structural Materials Technology and Materials \\ Odessa National Polytechnic University \\ 1 Shevchenko ave., Odessa, Ukraine, 65044 \\ wlebedev29@rambler.ru
}

\begin{abstract}
Stone cutting for construction work is carried out by disk diamond wheels the rotation speed of which, and, consequently, the cutting speed is $35-50 \mathrm{~m} / \mathrm{s}$. In view of the high intensity of the cutting process and intensive microchip formation, the process of stone cutting is accompanied by considerable dust formation, which can be both harmful and dangerous in the work.

The greatest danger is represented by dust particles, which dimensions are $5 \mu \mathrm{m}$ or less. These particles have the greatest pathogenic effect on the respiratory system of the human body. In addition, the settling time of these particles is measured in hours. Thus, even after the termination of work, the risk of dust exposure to the human body remains. Insignificant time of inhalation of these particles can lead a person to disability and death. Insurance payments in case of disability and compensation in case of death of an employee for these reasons all over the world amount to multibillion sums, which, even for this reason, makes the issue of combating this phenomenon very urgent.

In this paper, the process of generation of hazardous and harmful production factors arising as a result of dust formation during the stone cutting, the regularity of dust distribution by fractions, quantitative indicators of the process for improving equipment, as well as individual and collective means of personnel protection are determined. The shape and dimensions of the cutting grains of the cutting discs are studied in the paper, depending on the grain material and the grain size of the cutting disc. Thecurvature radii of the cutting grains depend on the grain material and the grain size of the cutting disc. The actual number of grains participating in cutting and, consequently, in dust formation is shown.

The dimensions of the dust particles depend on the graininess of the cutting discs and the processing regimes. Using the law of normal particle size distribution, the percentage of dust particles is determined depending on processing conditions. The rate of particle settling depends on their size and mass. The formation of a dust-air mixture and its probable concentration and chemical composition of dust depend on the chemical composition of the cutting materials.

Regularities are obtained, which can give an opportunity to improve the individual and collective protection of workers from this harmful production factor.
\end{abstract}

Keywords: cutting circle, grain size, cutting speed, microscrew size, dust, dust concentration.

\section{Introduction}

Stone building materials of natural origin include a wide range of products obtained from rocks.

Stone building materials of artificial origin, such as ceramic products, are made from natural clays, as well as from their mixtures with organic and mineral additives by molding, drying and calcining.

In view of the wide distribution of such materials, the question of their formation inevitably arises, which is accomplished by their cutting.

Most often, the cutting is carried out by circular diamond wheels which rotation speeds and, consequently, the cutting speed is $35 \ldots 50 \mathrm{~m} / \mathrm{s}$.

Due to the high intensity of the cutting process and intensive microchip formation, the process of stone cutting is accompanied by considerable dust formation, which can be both a harmful 
and a dangerous factor in the work. The greatest danger is represented by dust particles, which dimensions are $5 \mu \mathrm{m}$ or less [2]. The settling time of these particles is measured in hours. Thus, even after the termination of work, the risk of dust exposure to the human body remains. Insignificant time of inhalation of these particles can lead a person to disability and death. Insurance payments in case of disability and compensation in case of death of an employee for these reasons all over the world amount to multibillion sums [1], which even for this reason makes the issue of combating this phenomenon very urgent. Thus, the study of the dust formationprocess during stone cutting is topical, as it makes it possible to improve the protection of workers, on the one hand preserving their life and health, and on the other to obtain significant savings on insurance, since there is no need to pay them.

\section{Analysis of the literature data and formulation of the problem}

Recently, much attention has been paid to the sanitary and hygienic working conditions, in connection with which the issues of dustiness of air in workrooms are considered. This issue is devoted to such works as [2-4]. However, in these works, it is mainly concerned with the effects of dust on the human body, as well as the duration of dustsoaring in the atmosphere of the production room. Despite the importance of these issues, they do not cover the whole phenomenon - "dust in the work rooms".

In the works devoted to the stone cutting, the issue of dust generation is practically not considered. In general, the issues of dust flammability, the spread of flames in a dust cloud, the durability of tools during cutting and other issues are discussed.

So in $[5,6]$, questions of dust ignition are considered. This is an important issue to ensure the safety of work, but does not consider the mechanism of dust generation.

In [7], the authors consider the wear of segments of diamond saws when cutting granite. Issues of dust generation are not considered.

In [8], the authors study the process of natural stonecutting in quarries with equipment with chain saws equipped with diamond teeth. The problem of dust formation during cutting is not considered.

In [9], the authors study the process of flame propagation in a dusty medium. Despite the importance of the issue for labor protection and fire safety, the issue of dust formation in this work is not considered.

In [10], the authors study the problem of removing dust dispersions from quarries of natural stone. The issue is important for ensuring safe working conditions, but the dust formation process is not considered.

In [11], the authors study the effect of cutting modes on the power consumption when cutting a stone with a multi-disc tool. The question is important from the point of view of energy consumption, however the mechanism of dust formation is not considered.

In [12], the authors study the use of solid wastes for cutting granite as an alternative abrasive for hydroabrasive cutting of marble. In spite of the fact that the chip obtained from cutting granite is used for hydroabrasive cutting of marble, the problem of chip formation and, consequently, the issue of dust formation is not considered.

In [13], the authors study the problem of the durability and durability of stone-cutting tools. Chipping or dust formation is not considered.

In [14], the authors examine the issue of linear tests of stone cutting with the help of chisel tools for determining the principles of cutting and predicting the performance of chain saws. The tooth of the chain saw is considered as a kind of chisel and the cutting mechanism is investigated. This makes it possible to determine the conditions for the maximum productivity of the cutting process. Despite the fact that the productivity is determined by the volume of material removed by the tooth, that is, ultimately the amount of chips, the issue of dust formation during cutting is not considered.

In [15], the authors study the question of optimizing the cutting speed of block stone cutting machines to save energy. The problems of the cutting speed optimization are considered to 
minimize energy consumption. The issue is very important from the technological point of view, however, dust formation is not considered.

In [16], the authors study the influence of the dimensions of abrasive grain on the process of waterjet cutting of concrete. The issue of dust formation is not considered, since there is no dust in hydroabrasive cutting, but there may be dispersed water suspensions, which is not the subject of this article.

\section{The aim and objectives of research}

The aim of research is studying the process of dust generation during the stone cutting for construction works, to determine the quantitative parameters of this process and to study the regularities of the distribution of dust particles over size fractions, which will improve individual and collective means of protecting workers.

To achieve this aim, it is necessary to solve the following tasks:

1. Determine the shape and dimensions of the cutting grains of the cutting discs, depending on the grain material and the grain size of the cutting disc.

2. Determine the conditional curvature radii of the cutting grains, depending on the grain material and the grain size of the cutting disc.

3. Determine the actual number of grains participating in the cutting and, therefore, in the dust formation.

4. Determine the size of dust particles, depending on the grain size of the cutting discs and processing modes.

5. Using the law of normal particle size distribution, determine the percentage of dust particles, depending on processing conditions.

6. Determine the settling time of particles of different mass, the formation of a dust-air mixture and its probable concentration.

7. Determine the chemical composition of dust, depending on the cutting materials.

\section{Materials and methods for studying the patterns of dust formation during the cutting of stones for construction works}

Theoretical studies are carried out using mathematical modeling, experimental studies are performed using experimental design methods. Diamond cutting wheels with a diameter of $400 \mathrm{~mm}$ and samples made from granite are used in the experiments.

\section{Analytical and experimental studies}

Cutting stone, for today is the simplest and accessible method of shaping. This process ensures high precision of products and the cleanliness of their surfaces.

When cutting various materials, the dust content of air is much higher than the maximum allowable concentration, and the flying chips are the source of eye traumatism. Despite the many types of cutting, almost all of them come in two ways: cutting into dry and cutting with the use of cutting fluids.

Cutting "into dry" takes a big place among all kinds of work. From the point of view of labor protection, cutting "into dry" can be considered as a continuous generator of a dangerous and harmful production factor - dust. Dust when cutting "into dry" is a collection of microchips, which are cut with abrasive grains. The dimensions of these chips are very small from micrometer shares to several micrometers. Thus, the size ofthe chips makes it possible to create a dust suspension, the settling rate of which is very small and in large concentrations is in the working space during operation.

Dust is a dispersed system. Dusts of $1 \mu \mathrm{m}$ in diameter and smaller form an aerosol suspensionwith air.

The rate of dust settling increases as the diameter of the dust particles increases. The settling time of a dust particle with a diameter of $0.05 \mu \mathrm{m}$ from a height of $1 \mathrm{~m}$ equals 320 hours, a speck of $1 \mu \mathrm{m}$ in size passes the same path in 3 hours, and particles with a diameter of $100 \mu \mathrm{m}$ settle for 3 seconds [5]. Therefore, in the air entering the respiratory tract, there are relatively few particles 
with a diameter greater than $5 \mu \mathrm{m}$. The dependence of the settling rate of dust particles on their dimensions is shown in Fig. 1 [15].

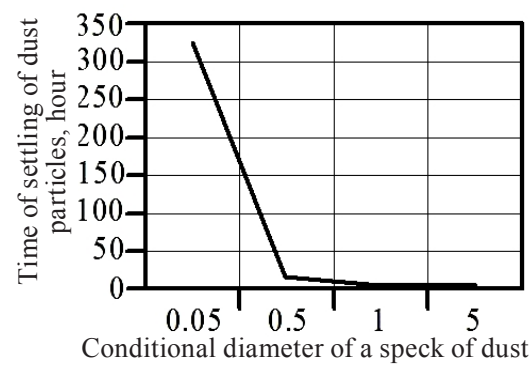

Fig. 1. Graph of sedimentation rate versus the size of grains

\section{1. Determination of the size of dust particles and patterns of dispersion of these dimensions}

It can be argued that abrasive grains are irregularly shaped polygons [17, 18], and the cutting element of the abrasive grain has, as a rule, a pyramidal shape, the angle at the tip of the cutting element is most often close to $90^{\circ}$. Each cutting element of the abrasive grain has a rounded top, with the curvature radius of this vertex depending on the grain size - large abrasive grains have large radii of the rounding of the vertices.

The scheme of formation of chips, proceeding from the shape of the abrasive cutting grain, is shown in Fig. 2.

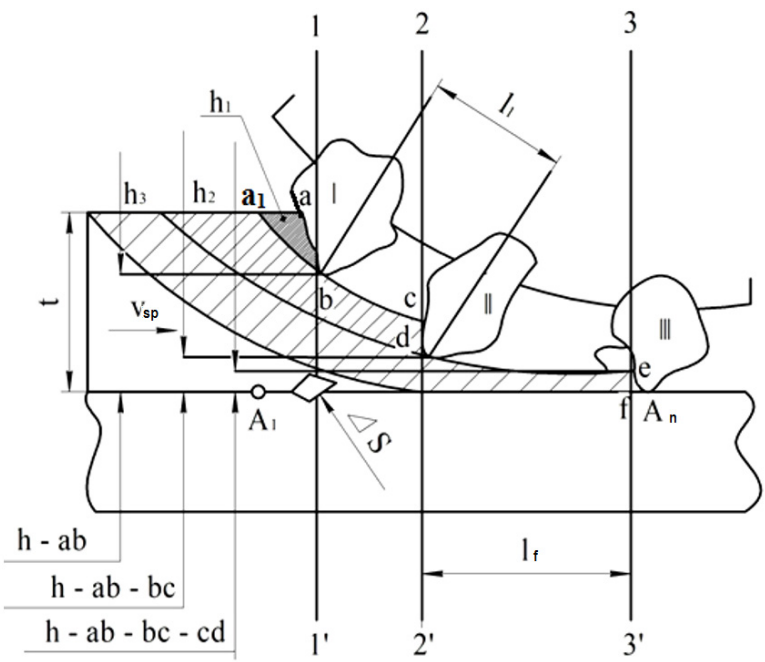

Fig. 2. Scheme of formation of chips (dust particles) when cutting a stone: $a_{1}$ - the trajectory of the cutting grain: $h_{1}, h_{2}, h_{3}-$ chip thickness, $l_{f}-$ the actual distance between the cutting grains, $\mathrm{t}$ - the cutting depth when grinding

To determine the thickness of the chip which is being cut by a cutting grain, it is necessary to know the following.

- rounding radius of the graintop (depends on the grain number of the grinding wheel);

- the actual distance between the cutting grains (only $10 \ldots 12 \%$ of the grains participate in the cutting operation $[17,18])$;

- the specific number of cutting grains per unit surface of the circle $z_{\mathrm{f}}$;

- the average distance between cutting grains $1_{\mathrm{f}}$;

- the average thickness of the cut by each grain $h$.

These values are determined by the method associated with the use of microthermocouples with an electrode diameter of $10 . .20 \mu \mathrm{m}$, partially described in [18, 19].

These investigations are carried out in the grinding of steels and cast irons. Samples of materials are electrically conductive and semi-artificial thermocouples "thermoelectrode - part" can 
be used, when the part itself serves as the second thermoelectrode. The convenience of using of such microthermocouples is obvious, but they cannot be used when cutting non-conductive stones. In this research artificial thermocouples "thermoelectrode - thermoelectrode"are used, which are more difficult to work with, Fig. 3.

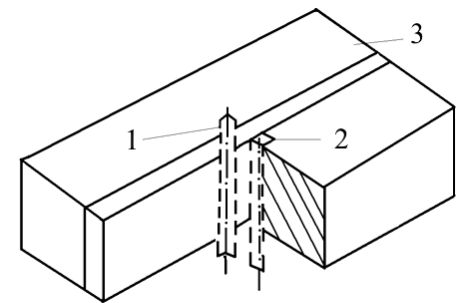

Fig. 3. A sample for measuring the temperature by a buried thermoelectrode: 1 - iron wire; 2 - constantan wire; 3 - tested sample

Thermoelectrodes are removed to the surface of the sample and are joined together by a circle (polished), forming a thermo-paste, the value of which is $5 . .10 \mu \mathrm{m}$, thus forming a low-inertia microthermocouple "iron-constantan", the characteristic heat pulse of which is shown in Fig. 4.

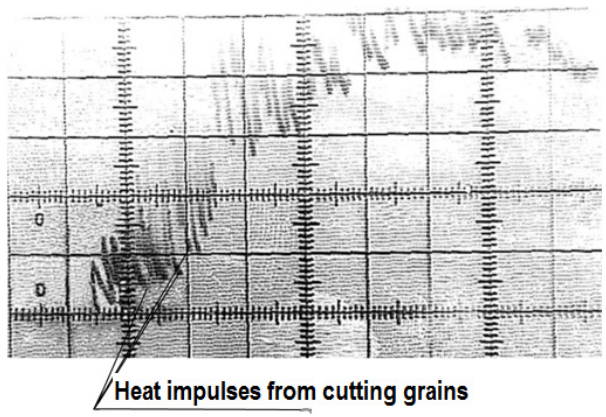

Fig. 4. Characteristic heat pulse from the microthermocouple

Knowing the sweep speed of the storage oscilloscope, it is possible to determine the number of cutting grains in the arc of contact of the circle with the cutting stone, the distance between the cuttinggrains, and the average chip thickness cut by each grain.

The thickness of the chips during cutting can be taken from the sources [17, 18], since in our studies they are practically confirmed. This value can be described by expression

$$
h=\frac{20 \cdot t \cdot v_{m} \cdot 1_{f}}{v_{w} \cdot \sqrt{D \cdot t}},
$$

where $\mathrm{v}_{\mathrm{m}}$ - the minute feed, $\mathrm{v}_{\mathrm{w}}$ - the rotation speed of the wheel, $\mathrm{t}$ - the feed per circle revolution, $1_{\mathrm{f}}$ - the actual distance between the cutting grains in the wheel, and D - the diameter of the wheel.

The average size of the shavings (dust grains) is shown in Fig. 5.

The number of chips (dust particles) formed in $1 \mathrm{~s}$ will obviously be

$$
\mathrm{n}_{\mathrm{sp}}=\mathrm{v}_{\mathrm{w}} \cdot \mathrm{S} \cdot \mathrm{z}
$$

where $\mathrm{n}_{\mathrm{sp}}$ is the number of shavings (dust particles) formed in $1 \mathrm{~s}$; $\mathrm{z}$ is the specific number of cutting grains per unit surface of the grinding wheel, equal to the results of our measurements

$$
\mathrm{z}=\frac{0.7}{\mathrm{~L}_{\mathrm{f}}^{2} \cdot \mathrm{R}_{\mathrm{z}}^{0.25}},
$$




$$
\begin{gathered}
\mathrm{L}_{\mathrm{f}}=3 \cdot 10^{-4} \cdot \mathrm{N}_{\mathrm{z}}^{0.65} \cdot \mathrm{N}_{\mathrm{ctr}}^{0.083}, \\
\mathrm{R}_{\mathrm{z}}=10^{-6} \cdot \mathrm{N}_{\mathrm{z}}^{0.85} \cdot \mathrm{K}_{\mathrm{z}},
\end{gathered}
$$

where $\mathrm{N}_{\mathrm{z}}$ - the number of grain of the circle, reduced to the granularity of abrasive wheels; $\mathrm{N}_{\mathrm{ctr}}-$ the number of the circle structure; $\mathrm{S}$ - the width of the cutting circle, $\mathrm{L}_{\mathrm{f}}$ - the actual distance between the cutting grains, $\mathrm{R}_{\mathrm{z}}$ - the conventional rounding radius of the tip of the cutting grain, $\mathrm{k}_{\mathrm{z}}-$ the coefficient of the grain material equal to 1 for electrocorundum, 0.8 for cubic boron nitride (CBN), and 0.7 for synthetic diamond.

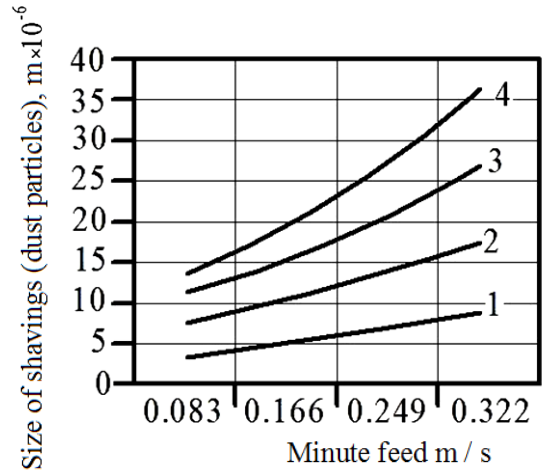

Fig. 5. Average size of shavings (dust grains) depending on the graininess of the circle and modes: $\mathrm{v}_{w}=35 \mathrm{~m} / \mathrm{s} ; \mathrm{t}-$ feed per revolution of the circle $0.01 \mathrm{~mm} ; 1$ - granularity 6 ; 2 - grain size 10; and 3 - granularity $16 ; 4$ - grain size 25

The specific amount of dust particles formed during cutting is shown in Fig. 6.

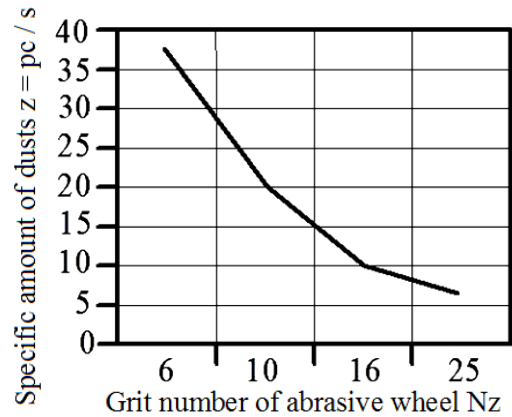

Fig. 6. Specific amount of dust particles during cutting

The minute concentration of dust during stone cutting, (with the working zone size $0,5 \times 0,5 \times 0,5 \mathrm{~m}=0,125 \mathrm{~m}^{3}$ ) can be within the limits of $1,68 \times 108 \times 0,28 \times 108 \mathrm{pcs} / \mathrm{m}^{3}$.

The greatest influence on the size of dust particles is provided by the speed of rotation of the circle $v_{w}$ and the feed per revolution of the wheel $t$. Analysis of formula (1) shows that the size of the dust particles is inversely proportional to the speed of the circle, i. e. when the speed of the circle increases, the size of the dust particles decreases. As for the feed per circle, the size of the dust particle is directly proportional to $t^{0.5}$. Thus, since cutting is not performed at velocities of less than $30 \mathrm{~m} / \mathrm{s}$, it is possible to expect a reduction in the size of the dust particles during the transition to high-speed cutting with speeds of about $50 \mathrm{~m} / \mathrm{s}$. Thus, the range of dimensions shown in Fig. 6 will change. The range of $0.5 \ldots 3.5 \mu \mathrm{m}$ will turn into a range of $0.35 \ldots 2.1 \mu \mathrm{m}$.

With regard to the feed per circle, then when cutting "in dry" values of more than $0.03 \mathrm{~mm} / \mathrm{rev}$ are practically not used. When using this value, it is possible to obtain a range of sizes of $0.86 \ldots 6 \mu \mathrm{m}$.

Conditionally, the dimensions of the abrasive grains in the size range that are given in the standards can be broken down into 3 fractions - medium, small and large. This means that with one 
grain number in the circle there are grains of different sizes. Accordingly, the larger grains protrude more out of the bundle, and, therefore, they remove larger shavings than small ones. It is possible to say with a high probability that the size of the shavings (dust grains) will also obey this law.

Typically, the size of the main fraction is $45 \%$, then the fine and coarse fraction is $27.5 \%$. The sizes of large and small fractions differ from the average by $11.5 \%$. If these patterns are applied to dust particles, the following values are (Table 1).

Table 1

Dimensions of dust particles formed during grinding, $\mu \mathrm{m}$

\begin{tabular}{|c|c|c|c|c|}
\hline $\mathrm{N}_{\mathrm{z}} \mathbf{V}_{\mathrm{sp}} \mathbf{m} / \mathbf{s}$ & 0,083 & 0,166 & 0,249 & 0,332 \\
\hline 6 & 0,$4 ; 0,45 ; 0,5$ & 0,$448 ; 0,50 ; 0,56$ & 0,$58 ; 0,65 ; 0,724$ & 0,$81 ; 0,9 ; 1,0$ \\
\hline 10 & 0,$67 ; 0,75 ; 0,84$ & $089 ; 1,0 ; 1,15$ & 1,$25 ; 1,4 ; 1,56$ & 1,$52 ; 1,7 ; 1,9$ \\
\hline 16 & 0,$98 ; 1,1 ; 1,22$ & 1,$34 ; 1,5 ; 1,67$ & 1,$88 ; 2,1 ; 2,34$ & 2,$06 ; 2,3 ; 2,56$ \\
\hline 25 & 1,$34 ; 1,5 ; 1,67$ & 1,$79 ; 2 ; 02,23$ & 2,$33 ; 2,6 ; 2,9$ & 3,$22 ; 3,6 ; 4,0$ \\
\hline
\end{tabular}

As can be seen from Table 1, the size of the dust particles will be those that have the greatest pathogenic effect on humans and the settling rate of which in the air will be several hours.

\section{2. Determination of the chemical composition of chips}

In the contact zone of the circle with the stone, a large amount of heat is formed during cutting. Part of this heat (about $10 \%$ ) goes to the shavings [20]. This is often enough to heat the chips to the combustion temperature.

Experiments [19] show that chips that arise when cutting sufficiently strong materials are small glowing or molten particles that fly tangentially to the point of the circle of the rotating wheel to which the sample is pressed. Molten chips or molten material particles, flying at high speed in the air, are heated even more. This is because under the influence of atmospheric oxygen there is intense oxidation - burning, which increases the temperature of the chips.

From Fig. 2 one can see that, when detached, chips rub against the front surface of grain ab, which can be regarded as the front surface of the cutting element. In this case, the chip temperature can be determined as the temperature of its friction against the front surface of the grain.

The heat flux generated by friction of the chip on the front surface of the cutting element (grain) is taken:

$$
\mathrm{q}_{\text {ind }}=\mathrm{P}_{\mathrm{zind}} \cdot \mathrm{v}_{\mathrm{w}} \cdot \mathrm{k}_{\mathrm{fr}} \text {, }
$$

where $\mathrm{q}_{\mathrm{ind}}$ - the heat flux generated by a single cutting grain; $\mathrm{k}_{\mathrm{fr}}$ - the coefficient of friction equal to 0.1 .

Specific heat flux in friction is determined on the basis that it is allocated on the area of a square shape with side h.

$$
\mathrm{q}_{\mathrm{sp}}=\frac{\mathrm{q}_{\text {ind }}}{\mathrm{h}^{2}}
$$

The chip temperature is determined taking into account the fact that only $10 \%$ of the heat goes to it $[20,21]$.

$$
\mathrm{T}_{\mathrm{ch}}=\frac{1.064 \cdot \mathrm{q}_{\mathrm{sp}}}{\lambda}\left(\frac{2 \cdot \alpha \cdot 1}{\mathrm{v}_{\mathrm{w}}}\right)^{0.5}
$$

where $\mathrm{q}_{\mathrm{sp}}$ - the specific heat flux, $\lambda$ - the thermal conductivity of the mineral, a - the thermal diffusivity of the mineral, $v_{w}$ - the rotation speed of the wheel, 1 - the length of the rubbing element. 
In Fig. 7 is shown the chip temperature when cutting a mineral with a complex composition - granite. Granites are very widespread in the continental crust. The density of granite is $2600 \mathrm{~kg} / \mathrm{m}^{3}$, the compressive strength is up to $300 \mathrm{MPa}$. The melting point is $1215 \ldots 1260{ }^{\circ} \mathrm{C}$. Mineral composition feldspar (acid plagioclase and potassium feldspar) - 60...65\%; quartz - 25...35 \%; mica (biotite) $-5 \ldots 10 \%$. A widely distributed chemical composition of such a mineral composition will be $\mathrm{KAlSi}_{3} \mathrm{O}_{8}+\mathrm{SiO}_{2}+\mathrm{Al}_{3} \mathrm{SiO}_{10}$. Calculations show that the chips (dust particles) are heated to high temperatures. If these temperatures are higher than the combustion temperature, then all the chips are burned. The combustion temperature of these minerals is quite high (slightly higher than the melting point). However, in the source [5] it is shown that if the metal or mineral is in the powder state, then the combustion temperature drops sharply. For example, the combustion temperature of titanium is above $1800{ }^{\circ} \mathrm{C}$, and in the powder state it decreases to $400{ }^{\circ} \mathrm{C}$. Therefore, dusts consisting of mineral oxides and its unburned particles can be expected.

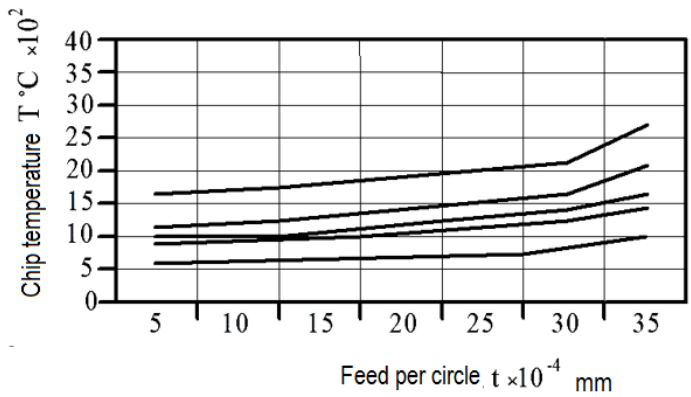

Fig. 7. Chip temperature when cutting with wheels of different grain size. Grit: $1-40 ; 2-25 ; 3-16 ; 4-12 ; 5-6 ; \mathrm{Vw}=35 \mathrm{~m} / \mathrm{s} ; \mathrm{Vsp}=0.166 \mathrm{~m} / \mathrm{s}$.

As can be seen from Fig. 7, in practically all modes of stone cutting, the chip temperature above the combustion temperature and the chemical composition of the chips are metal oxides that are part of the chemical composition of the cutting stones.

\section{Conclusions}

1. Hard stonecutting for construction work with diamond cutting discs is characterized by high dustiness of the working area air.

2. Abrasive and diamond grains of cutting wheels are polyhedral. The most common are grains in geometric form reminiscent of geometric figures - octahedral, trapezoid, tetrahedron, trihedral prism.

3. The radius of curvature at the tops of these figures is $5 \ldots 20 \mu \mathrm{m}$. The actual number of grains participating in cutting is no more than $15 \%$ of the total.

4. Dust during cutting is a collection of micro-chisels, which are cut with diamond grains. The dimensions of these chips are very small: from micrometer shares to several micrometers. Thus, the size of the chips makes it possible to create a dust suspension.

5. The settling time of the dust suspension depending on the material and the size of the dust particles are in the range of several minutes to several hours, which can create large concentrations of dust in the working space during operation within the limits of $1.68 \cdot 108 \ldots 0.28 \cdot 108 \mathrm{pcs} / \mathrm{m}^{3}$.

6. The size of chips when cutting is in the range $0.4 \ldots 6 \mu \mathrm{m}$. Dimensions of dust particles are in the range of the greatest pathogenic effect on humans.

7. The chemical composition of dust depends on the type of materials, as well as on the chip heating temperature, which, given the fine dust, is almost always higher than the burning temperature of a particular material. Thus, when cutting particularly complex stone structures, the dust composition can consist of oxides and dust particles of various elements, primarily those related to materials such as $\mathrm{K}, \mathrm{Si}, \mathrm{Al}$, and some others that are part of granites and basalts.

Knowledge of the patterns of dust formation, including the size of dust particles, concentration, chemical composition and sedimentation rate of dust particles, makes it possible in future studies to determine the severity of the cutting process and to develop an adequate system for protecting the worker. 


\section{References}

[1] Dorman, P. (2000). Ekonomika ohrany truda, zdorov'ya i blagosostoyaniya na proizvodstve. Geneva, 55.

[2] Pyl' i dyhatel'nye puti. Vse o spontannom pnevmotorakse. Available at: http://www.spontan.ru/ pnevmokoniozy/186-pyl-i-dyxatelnye-p\%20.uti.html

[3] Mushchenko, B. L. (2009). Calculation of the velocity of incidence of dust particles and an estimate of the degree of influence of various forces acting on the particle. Scientific Bulletin of the Voronezh State University of Architecture and Civil Engineering, 2, 58-63.

[4] Azarov, V. N. (2004). Comprehensive assessment of the dust situation and development of measures to reduce the dustiness of the air environment of industrial enterprises. Rostov on Don, 304.

[5] Shidlovskiy, A. A. (2012). Fundamentals of pyrotechnics. Moscow: Mechanical Engineering, 256.

[6] Eckhoff, R. K. (2003). Ignition of Dust Clouds and Dust Deposits: Further Considering Some Selected Aspects. Dust Explosions in the Process Industries. Houston: Gulf Professional Publishing, 385

[7] Sun, Q., Zhang, J., Wang, Z., Zhang, H., Fang, J. (2016). Segment wear characteristics of diamond frame saw when cutting different granite types. Diamond and Related Materials, 68, 143-151. doi: 10.1016/ j.diamond.2016.06.018

[8] Sariisik, A., Sariisik, G. (2012). Investigation of the cutting performance of the natural stone block production in quarries with armed-chain cutting machine. Proceedings of the Institution of Mechanical Engineers, Part C: Journal of Mechanical Engineering Science, 227 (6), 1291-1301. doi: 10.1177/0954406212460151

[9] Ogle, R. A. (2017). Confined unsteady dust flame propagation. Dust Explosion Dynamics. Oxford: Butterworth-Heinemann, 407-498. doi: 10.1016/b978-0-12-803771-3.00008-9

[10] Sairanen, M., Rinne, M., Selonen, O. (2017). A review of dust emission dispersions in rock aggregate and natural stone quarries. International Journal of Mining, Reclamation and Environment, 1-25. doi: 10.1080/17480930.2016.1271385

[11] Yurdakul, M. (2015). Effect of cutting parameters on consumed power in industrial granite cutting processes performed with the multi-disc block cutter. International Journal of Rock Mechanics and Mining Sciences, 76, 104-111. doi: 10.1016/j.ijrmms.2015.03.008

[12] Aydin, G., Kaya, S., Karakurt, I. (2017). Utilization of solid-cutting waste of granite as an alternative abrasive in abrasive waterjet cutting of marble. Journal of Cleaner Production, 159, 241-247. doi: 10.1016/j.jclepro.2017.04.173

[13] Rosa, L. G., Fernandes, J. C., Anjinho, C. A., Coelho, A., Amaral, P. M. (2015). Long-term performance of stone-cutting tools. International Journal of Refractory Metals and Hard Materials, 49, $276-282$. doi: 10.1016/j.ijrmhm.2014.05.021

[14] Copur, H. (2010). Linear stone cutting tests with chisel tools for identification of cutting principles and predicting performance of chain saw machines. International Journal of Rock Mechanics and Mining Sciences, 47 (1), 104-120. doi: 10.1016/j.jirmms.2009.09.006

[15] Bilim, N. (2012). Optimum cutting speed of block-cutting machines in natural stones for energy saving. Journal of Central South University, 19 (5), 1234-1239. doi: 10.1007/s11771-012-1134-y

[16] Karakurt, I., Aydin, G., Aydiner, K. (2010). Technology effect of the abrasive grain size on the cutting performance of concrete in awj technology. Technology, 13 (3), 145-150.

[17] Lebedev, V., Chumachenko, T. V. (2009). The actual distance between the cutting grains and the specific number of cutting grains per unit surface of the elbor wheel. Problemy tehniki, 3, 128-136.

[18] Lebedev, V., Al'-Adzhelat, S. A. (2009). The radius of the rounding of the CBN grains and the average size of the cuttings being cut by the cutting grain. Problemy tehniki, 4, 76-85.

[19] Lebedev, V., Al'-Adzhelat, S. A. (2013). Analytical determination of cutting forces and temperatures by a single elbor grain. Vestnik Har'kovskogo nacional'nogo tekhnicheskogo universiteta sel'skogo hozyaistva, 81, 263-270.

[20] Kordikova, E. I. (2013). Thermal effects in friction. Temperature at the contact surface. Minsk, 45. Available at: http://elib.belstu.by/bitstream/123456789/6050/1/tribotexnika_ehl_konspekt_lekcii.pdf

[21] Azarov, V. N., Bessarab, O. I., Kabaev, O. V. (2010). Theoretical studies of the sedimentation rate of fine dust in the air of working rooms of engineering and construction industry enterprises. Bulletin of Volg. GASU, 17 (36), 102-105. 